\title{
An ANN Approach to Demand Forecasting in Retail Trade in Bangladesh
}

\author{
M. Ahsan Akhtar Hasin, Shuvo Ghosh, and Mahmud A. Shareef
}

\begin{abstract}
For a small retail trading chain, demand forecasting is the main driver to effectiveness and efficiency. However, as large number of varied models and products are marketed through a super market, several attributes affect forecasting. Because of these affecting parameters, nonlinearity arises. As a result, traditional forecasting approaches can not provide good estimation of demand. A fuzzy neural network analysis can provide better solution in this case. This research first analyzed the trend and seasonality patterns of a selected product in a retail trading chain in Bangladesh. Then demand was forecasted using traditional Holt-Winter's model. The same was done again using artificial neural network (ANN) with fuzzy uncertainty. Finally, the errors, measured in terms of MAPE, were compared for finding the best fitting forecasting approach. The research found that the error levels in Holt-Winter's approach are higher than those obtained through fuzzy ANN approach. This is because of influence of several factors on demand function in retail trading system. It was also observed that as forecasting period becomes smaller, the ANN approach provides more accuracy in forecast.
\end{abstract}

Index Terms - Nonlinear demand estimation, retail trading chain, Holt-Winter's approach, neural network analysis.

\section{INTRODUCTION}

An efficient supply chain is the key to many of the business parameters, which is, as a whole, the main determinant of customer satisfaction. Although, a large number of retail chain are of pure trading type, there may be some super chains with minor contribution in manufacturing as well. In Bangladesh, a few large retail supermarkets exist, which are involved in pure trading. For a small retail sales outlet, demand forecasting is the main driver to effectiveness and efficiency. However, as large number of varied models and products are marketed through a super market, a huge amount of data has to be effectively managed Additionally, a large number of demand attributes affect forecasting. Availability of data, time horizon to forecast, length of past records, trends of past demand, accuracy required, etc. are the major attributes that affect forecasting process [1]

Manuscript received on March 9, 2011.

Dr. M. Ahsan Akhtar Hasin is a Professor in the Department of, Industrial and Production Engineering (IPE) at Bangladesh University of Engineering and Technology (BUET), Dhaka-1000, Bangladesh. Email: aahasin@ipe.buet.ac.bd

Mr. Shuvo Ghosh is an Assistant Professor in the Department of, Industrial and Production Engineering (IPE) at Bangladesh University of Engineering and Technology (BUET), Dhaka-1000, Bangladesh.

Dr. Mahmud Akhtar Shareef is an Associate Professor in the School of Business at North South University, Dhaka, Bangladesh.
An efficient and accurate demand forecasting system can play a major role in minimizing inventory costs of a super market. It must be noted that inventory cost is the single most important element of total cost for a super market. As such minimization of inventory cost should be of prime importance. Thus, an optimum forecast is essential [2].

Although the market share of super stores in Europe and the USA is really significant in retail business, it is not the same in a developing country, like Bangladesh. Traditionally, the retail business in Bangladesh is dominated by small independent grocery stores. However, the recent trend in the capital of Bangladesh, the mega city of Dhaka, with a population of 15 million, has changed. Super markets are rapidly gaining market share in retail business. Driven by changing life style, strong growth of middle class group, coupled with favorable demographic pattern, organized large stores concept is expanding very fast. Currently there are 35 large super markets only in the city of Dhaka. Based on recent growth of super markets in Dhaka, it is expected that the overall retail market share of the super markets will increase rapidly in the next few years. As such an efficient inventory management system, coupled with an accurate forecasting system has become essential for such chain markets.

This research study uses the traditional Holt-Winter's model for establishing basic forecasting function, which subsequently has been compared against neural network analysis so as to select the best fitting forecasting approach.

\section{LITERATURE REVIEW}

In today's demand-driven trading supply chain, being successful means finding the right balance between supply and demand, between levels of inventory at different stages of the chain, and between availability of materials and operational cost [3], [4]. Reports reveal that a 5\% improvement in demand forecasting accuracy correlates to a $10 \%$ improvement in order perfection [5].

As far as accuracy in judgmental adjustments are concerned, Eroglu and Croxton explored the effects of particular individual differences, specifically personality, motivational orientation, and work locus of control, on forecasting biases. The results indicate that a forecaster's personality and motivational orientation have significant effects on forecasting biases, whereas work locus of control has no effect on forecasting biases [6].

A super shop may have thousands of products on its list. While manual forecast may be infeasible for thousands of fast moving items, automated tools have been suggested for a few important items, although available automated tools 
developed so far can not ensure optimality in replenishment [6].

A number of research projects have demonstrated that the efficiency of inventory systems does not relate directly to demand forecasting performance, as measured by standard forecasting accuracy measures. When a forecasting method is used as an input to an inventory system, it should therefore always be evaluated with respect to its consequences for stock control through accuracy implications metrics, in addition to its performance on the standard accuracy measures. In this paper we address the issue of judgementally adjusting statistical forecasts for 'fast' demand items, and the implications of such interventions in terms of both forecast accuracy and stock control, with the latter being measured through inventory volumes and service levels achieved. We do so using an empirical dataset from the pharmaceutical industry. Our study allows insights to be gained into the combined forecasting and inventory performance of judgmental estimates. It also aims to advance the practice of forecasting competitions by arguing for the consideration of additional (stock control) metrics when such exercises take place in an inventory context [7].

Some researchers contrast the forecasting performance of alternative panel estimators, divided into three main groups: homogeneous, heterogeneous and shrinkage/Bayesian. Via a series of Monte Carlo simulations, the comparison is performed using different levels of heterogeneity and cross sectional dependence, alternative panel structures in terms of $T$ and $N$ and the specification of the dynamics of the error term. To assess the predictive performance, we use traditional measures of forecast accuracy (Theil's U statistics, RMSE and MAE), the Diebold-Mariano test, and Pesaran and Timmerman's statistic on the capability of forecasting turning points. The main finding of our analysis is that when the level of heterogeneity is high, shrinkage/Bayesian estimators are preferred, whilst when there is low or mild heterogeneity, homogeneous estimators have the best forecast accuracy [5].

Demand forecasting is a crucial aspect of the planning process in supply-chain companies. The most common approach to forecasting demand in these companies involves the use of a computerized forecasting system to produce initial forecasts and the subsequent judgmental adjustment of these forecasts by the company's demand planners, ostensibly to take into account exceptional circumstances expected over the planning horizon. Making these adjustments can involve considerable management effort and time, but do they improve accuracy, and are some types of adjustment more effective than others? However, a detailed analysis revealed that, while the relatively larger adjustments tended to lead to greater average improvements in accuracy, the smaller adjustments often damaged accuracy. In addition, positive adjustments, which involved adjusting the forecast upwards, were much less likely to improve accuracy than negative adjustments. They were also made in the wrong direction more frequently, suggesting a general bias towards optimism. Models were then developed to eradicate such biases. Based on both this statistical analysis and organizational observation, the paper goes on to analyze strategies designed to enhance the effectiveness of judgmental adjustments directly [8].

A wrong or inaccurate forecast leads to larger stock buildups, which increases the holding cost and partly ordering cost too. It must be noted that for a retailer, these costs consititue the bulk major part of operational cost, in contrast to a production organization [8]. Thus, many companies are pressured to control warehousing costs by improving their warehousing productivity. To cope with such warehousing challenges, a specific decision support system (DSS) that incorporates several computer-based models into the warehouse decision-making process has been proposed. These models include: a simulation model based on computer-aided design, an analytic hierarchy process, and a forecasting technique. This is specifically useful for a large retail market with high degree of variations in products in the shelves [9]. This necessitates an optimal forecast.

Collaborative forecasting has also been emphasized by many researchers for better performance of two consecutive stages of supply chain. To measure the degree of collaborative forecasting and planning, the concept of collaboration has been extended to even process opaertion. Reports reveal that this type of collaborative forecasting and materials/product planning helps overall performance of organizations [10]. However, this may not lead to optimality in forecasting and planning. This paper develops an optimality model to supplement the idea of collaboration in a supply chain.

Findings also show that the customer-supplier (manufacturer-retailer too) relationship and automatic data communication and registration have significant impact on the perceived quality of forecast information received from a downstream customer in the supply chain. The reliability and timeliness of the forecast information are affected to about the same extent by both the relationship type and the data communication. This necessitates e-commerce between manufacturer and retailer [11]. In case of recent trend of product acquisition by chain super shops from the manuifacturers, e-commerce has gained momentum in the USA, European marketrs and Bangladesh too.

Classical time series methods can not deal with forecasting problems that has both qualitative and quantittaive judgmnental inputs. In such a case, the values need to be expressed in linguistic terms. Song and Chissom presented the theory of fuzzy time series to overcome the drawbacks of the classical time series methods [12].

In case of nonlinearity in data set, several researchers suggested to use neural network analysis [3[, [4]. In case of nonlinear pattern, reports reveal that artificial neural network (ANN) has powerful pattern recognition, classification and prediction capability. Thus, one of the major application area of ANN is forecasting [13].

The focus of this research work is to apply ANN, incorportaing uncertainty, in forecasting the demand of varieties of products in chained retail stores. It is to be noted that this research work addresses forecasting for nonlinear pattern of demand, which is the reality, although majority of the research works focused on traditional linear pattern of demand, which is unrealistic, albeit easy to solve. 


\section{NATURE OF A CHAIN SUPER MARKET}

From inventory management point of view, a super market is basically a super sales store, which keeps in its large stock a huge variety of all most all kinds of products, ranging from daily merchandizing items, to decoration items, to even power tools. The trend of shopping behavior of urban people has strengthened the market position of super stores in retail business. In a super market, demand forecasting is the activity of estimating the quantity of a product or a product line that consumers will purchase in a certain time frame. It requires a good database and information system to track inflow and disbursements of different kinds of goods. The amounts of inflows and outflows of varieties of products necessitate an optimum forecasting system.

In a production industry, types of products produced vary in a small range. Thus, forecasting is not too difficult. But in a super market, a wide variety of products is procured and sold every day. This makes forecasting far more complex. An optimal algorithm is, thus, essential. Additionally, it must be noted that this optimal forecasting system has to deal with a large database of varied products.

\section{Retail Demand Forecasting Problem}

Understanding the underlying demand patterns for a particular product means that outlets can be re-stocked in sufficient time to cope with changes in consumer demand. For products those are perishable or have a short shelf-life, this issue is more critical than the slower moving products with smaller demand requirements. The super market chains face additional problems in terms of number of stores, slow and erratic sales for many items at the store level, assortment instability, promotional activity, and price changes [14].

Modern demand forecasting systems provide new opportunities to improve retail performance. Although the art of deterministic demand estimation of individual merchant may never be replaced, it can be augmented by an efficient, objective and scientific approach to forecasting demand. Nevertheless it remains a difficult task. Point of Sales automation through large-scale system may be an aid to handle the mass of retail data - organizing it, mining it and projecting it into future customer behavior. An ecommerce network facilitates this automated data collection, which is further facilitated by statistical analyzers.

\section{A Retail Chain In BANGLAdesh}

The chain super market under consideration has more than 8000 different types of items. Currently, this super market uses weighted moving average method, with linear assumption. This assumption never takes into account the demand influencing factors.

This research identified several demand influencing factors for inclusion in the forecasting model, three being outlined below.
1. Demand varies in two periods of a month, i.e. demand remains higher in the first half, where as it is low in the later half.

2. Demand remains higher in weekends, holidays and before major festivals.

3. Promotional programs affect demand.

However, the model developed here can accommodate as many variables as can be identified without any customization, since the model uses the powerful training aspect of neural network analysis against past demand patterns, which includes all practically acting variables. In order to ensure this, past data for a long period is essential. This study uses five years' data for trend analysis.

This study uses a very fast moving item, Noodles, for exemplary demand forecasting. It was found that because of the influence of the acting variables, the demand trend was never linear. In such a case, it is practically impossible to accurately forecast the demand using the traditional linear model. It is essential to develop an evolutionary algorithm to address such problem. It has been stated earlier that a neural network model can address the problem with good level of accuracy. This research applied neural network analysis for forecasting the demand of noodles in a large chain super market in Dhaka, the capital city of Bangladesh.

\section{PROBlem Formulation AND ANALYSIS}

As the demand of items in a super market chain is nonlinear because of existence of multiple influencing variables, neural network analysis was chosen for problem formulation. The network architecture was prepared by deciding number of input nodes, number of output nodes, number of hidden layers and hidden nodes, transfer function, training algorithm, bite size in the input nodes, data normalization process, and ratio of training-testing samples.

The 11 demand influencing variables were used as input nodes, as outlined below:

1. The day is a weekend, or is not an input node.

2. The day is a holiday, or is not an input node.

3. The day falls in a festival period.

4. Promotional activity, like free item offer and price discount.

5. Promotional activity, like lottery.

6. Availability of items on the shelf

7. Price range of the item- low, medium and high. Thus this node has three different input information.

8. The day falls in the first or second half of the month.

9. Consumption rate, like fast moving, slow moving, medium.

10. Brand loyalty category.

11. Climate or the season.

The algorithm has only one target output - the daily forecast amount. Thus, there is only one output node. The algorithm can forecast the demand up to 15 days, i.e. half of the month.

The combined aggregation and disaggregation of demand follows the algorithm given below (Fig. 1) [5]. 


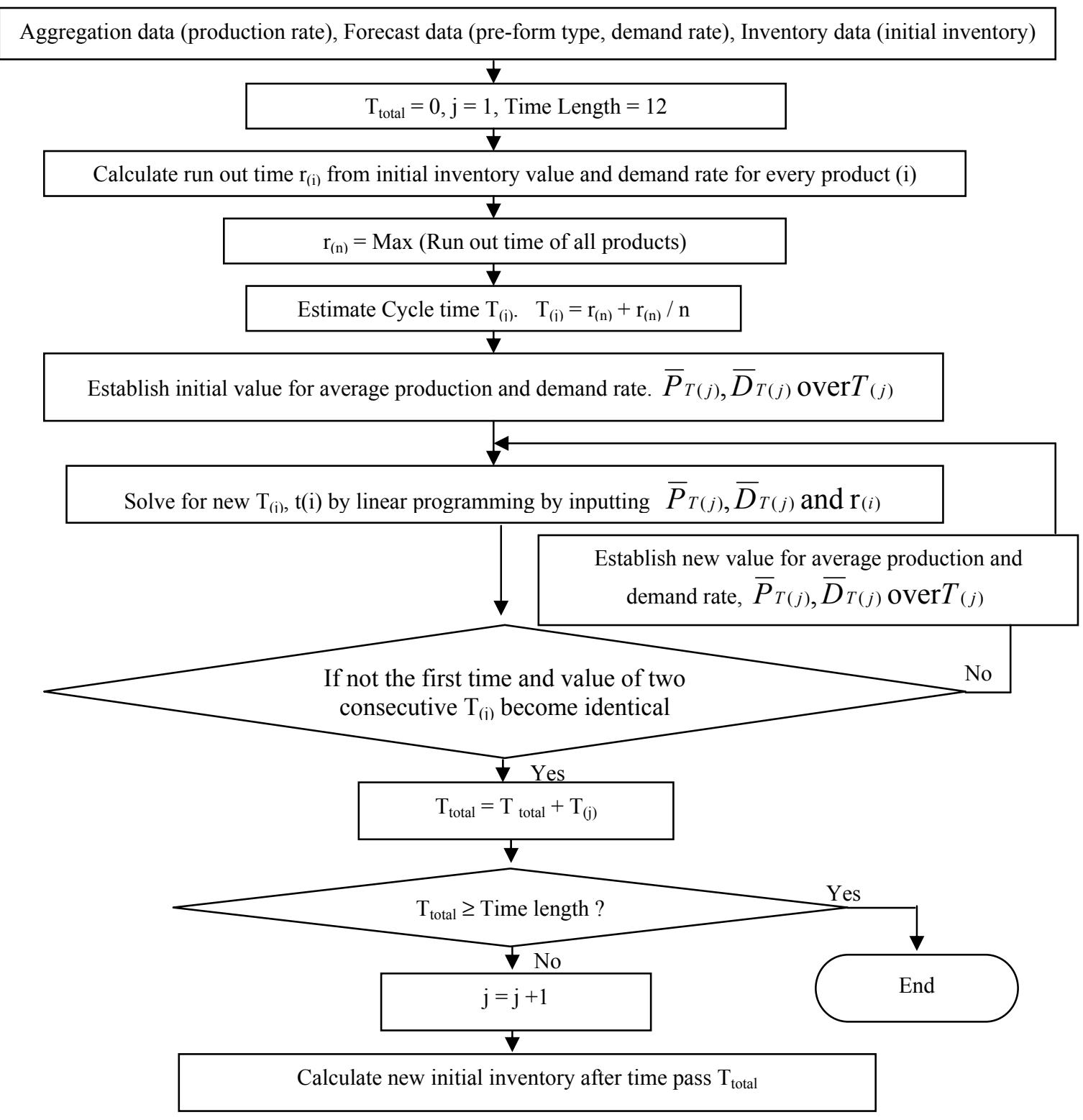

Fig 1: Aggregation-disaggregation plan.

The algorithm uses one hidden layer, which is found adequate and effective for forecast problem. The higher number of hidden layers may have more accurate mapping of nonlinear relationship among the input and output nodes. But as this makes the training process more complex and time consuming, this is traded off through only one layer.

The network training is actually an unconstrained nonlinear minimization problem. Thus, it perfectly suits the requirements of forecasting in a super market chain with multiple influencing variables. First, the training data set, which basically represents the past demand trend, was entered into the input nodes. The activation values of the input nodes were weighted and accumulated at each node in the first hidden layer. The total was then transformed by an activation function into the node's activation value. This transformed value acted as input to the final computation. The training algorithm was used to find the weights that minimize overall error measure. The back propagation method was used for training data.
The neural network model was formulated in MATLAB ver. 2008. The main computational algorithm with codes is given below. However additional codes need to be developed for supplementary functions, such as input-output function, graph development function, etc. The results of neural network analysis were compared against a widely used technique, the Holt-Winter's model [16].

\section{Training algorithm structure:}

function train_fn

$\%$ Data from File (Data range in excel file 2-10951)

data_all = xlsread('DatafileANN.xls','Practical','B3:M1097'); $\mathrm{j}=1$;

for $\mathrm{i}=1: 1095$

data(i,:) = data_all(j,:);

$\mathrm{j}=\mathrm{j}+\mathrm{1}$;

end

clear data_all; 
$\mathrm{t}$ row $=1064 ; \% \mathrm{t}$ row (Number of training rows)

t_column $=11 ; \% \bar{t}$ _column (Number of training column)

$\mathrm{p}=$ data(1:t_row, 2:t_column+1);

$\mathrm{t}=$ data(1:t_row, $1: 1)$;

$\%$ Formating

$\mathrm{p}=\mathrm{p}^{\prime}$

$\mathrm{t}=\mathrm{t}^{\prime}$

$\%$ Normalization

$[\mathrm{pn}, \mathrm{ps}]=\operatorname{mapminmax}(\mathrm{p})$;

$[\mathrm{tn}, \mathrm{ts}]=\operatorname{mapminmax}(\mathrm{t})$;

\section{$\%$ Network Creation}

net $=$ newff(pn,tn,6, \{'tansig' 'tansig' $\}$, 'traingdm');

$\%$ Parameter Setting

net.trainParam.epochs $=50000$;

net.trainParam.goal $=0.00001$;

net.trainParam.show $=\mathrm{NaN} ; \%$ Hide Outputs

$\%$ net.trainParam.mem_reduc $=4$;

net_backup = net;

$\%$ Training with Validation

net.divideParam.trainRatio $=0.8$;

net.divideParam.valRatio $=0.2$;

net.divideParam.testRatio $=0.0$;

[net,tr] = train(net,pn,tn);

net $=$ net_backup;

\% Parameter Update for final Training

net.trainParam.epochs = length(tr.epoch) - 1;

net.divideParam trainRatio $=1$;

net.divideParam.valRatio $=0$;

net.divideParam.testRatio $=0$;

\section{$\%$ Final Training}

net $=$ train(net,pn,tn);

save trainnet1 net ps ts data t_row t_column;

$\% \% \% \% \% \%$

xi_ori=net.iw $\{1,1\} ; \%$ Input Layer Weight Matrix

xl_ori=net.lw $\{2,1\}$;

[res_ori, min_nn, max_nn, std_nn,target, output_nn]

$=\overline{\text { sim_fn}}\left(\mathrm{xi}\right.$ - ori, $x 1 \_$ori, 15); \% Result before PSO

result_ann $=$ [res_ori min_nn max_nn std_nn] $\%$ Result With $\mathrm{NN}$ weight

save sim_result_for_graph1 target output_nn;

\%target
\%Saving the Network

Graph.

\section{Simulation algorithm structure:}

function [MAPE, MIN, MAX, STD, t, y1] = sim_fn(wi, wl, days)

load trainnet1; \%Load network and Data

$\%$ Modify Network

net.iw $\{1,1\}=$ wi;

net.lw $\{2,1\}=w 1$;

$\mathrm{s} \_$start $=\mathrm{t} \_$row $+1 \%$ Simulation Starts where train ends

s_end $=$ s_start + days $-1 ; \%$ Simulation end

$\mathrm{p}=$ data(s_start:s_end, $2: \mathrm{t} \_$column +1$)$;

$\mathrm{t}=$ data(s_start:s_end, $1: 1)$;

$\mathrm{p}=\mathrm{p}^{\prime}$

$\mathrm{t}=\mathrm{t}^{\prime}$

pn = mapminmax ('apply',p,ps);

tn $=$ mapminmax ('apply',t,ts);

$\%$ Simulation

$\mathrm{Y}=\operatorname{sim}($ net,pn,[],[],tn);

$\%$ Calculation

y1 = mapminmax ('reverse',Y,ts);

err $=$ abs $(\mathrm{t}-\mathrm{y} 1) ; \%$ Absolute Error

per_err $=($ err.$/ \mathrm{t}) * 100 \%$ Percentage Error

MAPE $=$ mean $($ per err $)$

$\mathrm{MIN}=\min ($ per_err);

MAX $=\max ($ per_err);

$\mathrm{STD}=$ std(per_err);

An extension of Holt's model, known as Holt-Winter's model can take into account both trend and seasonality [14], [16]. This is thus very useful for forecasting in super market chain. The standard Holt-Winter's model is expressed with three smoothing coefficients $\alpha, \beta$ and $\gamma$, incorporated in a set of equations [17].

The first step of demand forecasting involves collection of demand data, which is a direct measurement of sales volume for one year. A partial sales data of selected items are given in Table1.

TABLE 1: DEMANDAND DATA OF SELECTED RETAIL ITEMS

\begin{tabular}{|c|c|c|c|c|}
\hline Product category & Product name & \multicolumn{3}{|c|}{ Quarterly demand for three quarters of a year } \\
\hline \multirow{4}{*}{$\begin{array}{c}\text { Daily Grocery } \\
\text { (Kilograms) }\end{array}$} & Fish type-1 & 252 & 270 & 310 \\
\hline & Meat type-1 & 360 & 420 & 380 \\
\hline & Red Bean & 180 & 172 & 165 \\
\hline & Potato & 720 & 830 & 910 \\
\hline \multirow{5}{*}{$\begin{array}{l}\text { Weekly/Monthly } \\
\text { grocery (per pack or kg } \\
\text { or liter) }\end{array}$} & Noodles-1 & 282 & 310 & 302 \\
\hline & Noodles-2 & 243 & 255 & 262 \\
\hline & Soybean oil & 302 & 353 & 330 \\
\hline & Salt & 238 & 245 & 256 \\
\hline & Wheat flower & 432 & 480 & 502 \\
\hline \multirow{3}{*}{ Utensils (per piece) } & Spoons-1 & 280 & 324 & 320 \\
\hline & Crockery-1 & 180 & 158 & 197 \\
\hline & Cleaning mat & 189 & 280 & 302 \\
\hline \multirow{3}{*}{ Clothings (per piece) } & T-shirt-1 & 156 & 180 & 172 \\
\hline & Woven shirt & 272 & 289 & 322 \\
\hline & Handkerchief & 161 & 143 & 195 \\
\hline
\end{tabular}


Based on the demand data given in Table 1, a sensitivity analysis has been done. The absolute demand values have been converted to normalized values using equation1. The seasonal impact on demand has been captured from variations in demands in three quarters in a year.

$$
N S V=\sum_{i=1}^{n} w_{i} s_{i}
$$

where, NSV = Normalized demand values; $\mathrm{W}=$ sales volume; $\quad \mathrm{i}=$ period/quarters; $\mathrm{s}=$ percentage change in volume;

$$
D P F=N S V / w \quad M C F=N S V / m ; \quad S F=w / i s ;
$$

where, $\mathrm{DPF}=$ Demand factor, $\mathrm{MCF}=$ Marginal cost factor; $\mathrm{SF}=$ Seasonal factor; $\quad \mathrm{m}=$ marginal cost.

Using above set of equations, a demand matrix is prepared for input in the "Training algorithm", described earlier. The output, in the form of demand matrix, obtained from MTALAB is shown Table 2.

\begin{tabular}{|c|c|c|c|c|}
\hline Product category & Product name & Quarterly Normali & $\begin{array}{l}\text { Ies (Demand fac } \\
\text { factor) }\end{array}$ & st factor, seasona \\
\hline \multirow{4}{*}{ Daily Grocery } & Fish type-1 & $1(1.5,2,1)$ & $2(1.5,1,1)$ & $1(1.5,1,2)$ \\
\hline & Meat type-1 & $1.8(1,2,1)$ & $2.2(1,2,1,3)$ & $2.1(1,2,2)$ \\
\hline & Red Bean & $0.9(1.1,1,1)$ & $0.8(1.4,2,1)$ & $0.9(1.2,2,3)$ \\
\hline & Potato & $1(2,2,3)$ & $2(2,2,3)$ & $2(2,2,3)$ \\
\hline \multirow{5}{*}{$\begin{array}{c}\text { Weekly/Monthly } \\
\text { grocery }\end{array}$} & Noodles-1 & $1.4(0.6,2,1)$ & $1.9(0.5,2,2)$ & $1.6(0.7,1,2)$ \\
\hline & Noodles-2 & $1.5(0.5,2,2)$ & $2(0.6,3,2)$ & $1.7(0.8,2,2)$ \\
\hline & Soybean oil & $2(0.7,2,1)$ & $1.8(1.0,2,1)$ & $1.7(0.8,2,2)$ \\
\hline & Salt & $2.5(1.8,1,3)$ & $2.5(1.1,1,2)$ & $2.2(1.4,1,3)$ \\
\hline & Wheat flower & $1.5(0.4,2,3)$ & $1.5(0.3,3,3)$ & $1.5(0.8,1,3)$ \\
\hline \multirow{3}{*}{ Utensils } & Spoons-1 & $1(1,3,3)$ & $1.1(1,3,4)$ & $1.2(1,3,3)$ \\
\hline & Crockery-1 & $2(1,4,1)$ & $2(1,3,1)$ & $2(1,3,3)$ \\
\hline & Cleaning mat & $1.1(1,2,1)$ & $1.1(1.2,1,1)$ & $1.2(1.2,2,2)$ \\
\hline \multirow{3}{*}{ Clothings } & T-shirt-1 & $2(3.7,2,1)$ & $2(4.2,2,2)$ & $1.5(1,2,1)$ \\
\hline & Woven shirt & $2.1(2.9,3,1)$ & $2.1(2.6,3,2)$ & $2.2(2.2,3,2)$ \\
\hline & Handkerchief & $2(1,1,1)$ & $1.9(1.5,1,1)$ & $2(0.9,2,1,1)$ \\
\hline
\end{tabular}

TABLE 2: DEMAND MATRIX OF SElECted RETAIL ITEMS.

The second step of analysis involves simulation, the algorithm being discussed earlier. The simulation includes sensitivity analysis in the form of graphs, as shown Figures 2 to Figure 4. An Excel-based plot of past data on daily demand, as shown in Figure 2, for the retail chain under consideration also revealed that a high error level exist in forecasting. The demand analysis of the selected products has shown that it has both seasonal and trend effects. This is in fact a very common scenario in case of majority of the food items in a retail chain.

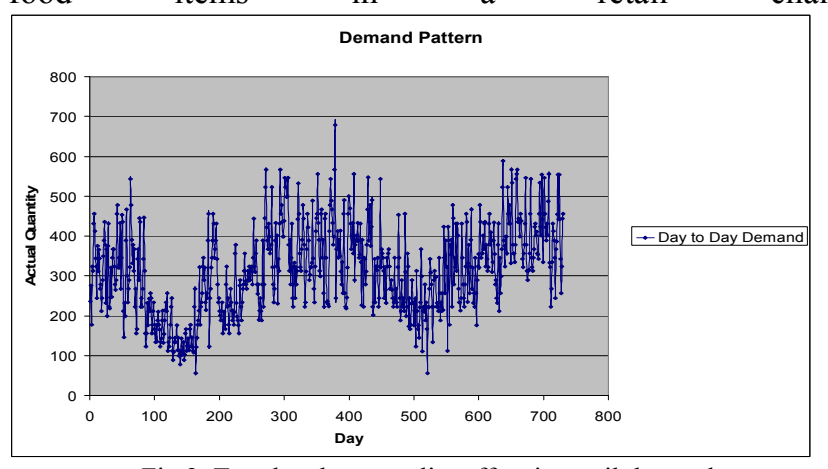

Fig 2. Trend and seasonality effect in retail demand.

As Holt-Winter's model is highly useful and widely used in retail demand forecasting, it has thus been used in this study for benchmark analysis for neural network model. The model showed a considerable deviation of actual daily demand against forecast, as shown in Figure 3.

On the other hand, the neural network model shows significantly less deviation of actual against forecast, as shown in Fig 4.
Demand Pattern (Day to Day Demand)

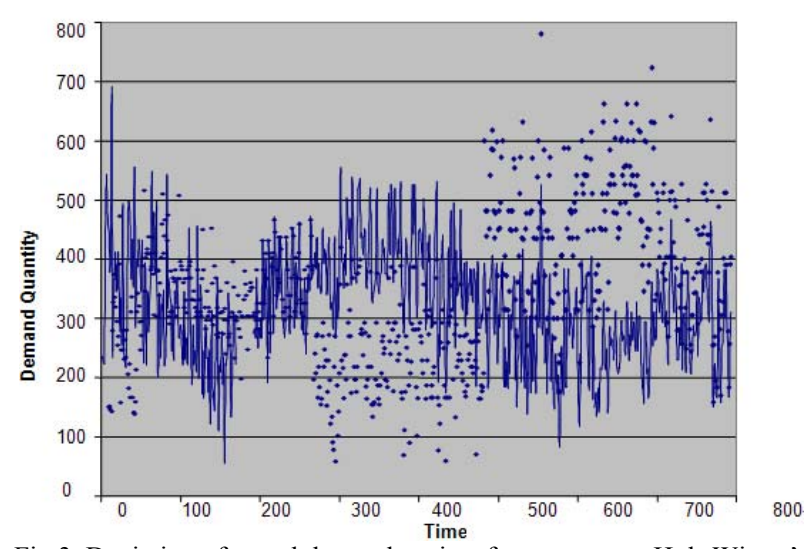

Fig 3. Deviation of actual demand against forecast as per Holt-Winter's model.

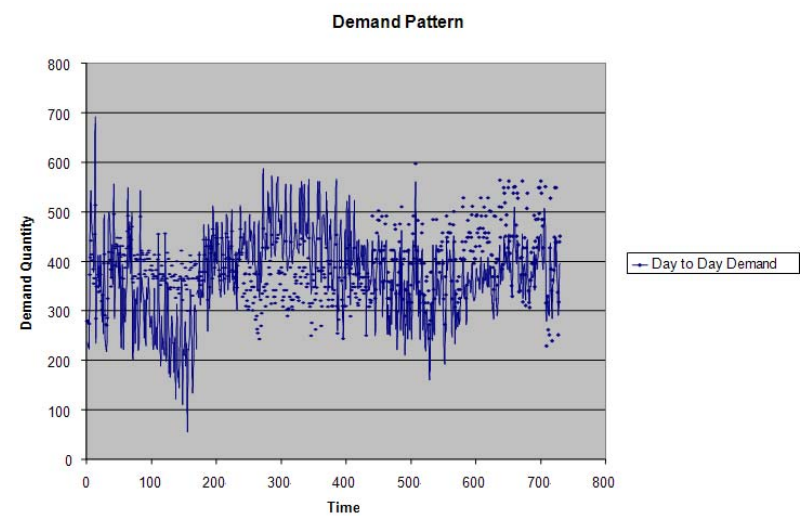

Fig 4. Deviation of actual demand against forecast as per neural network model. 
The resulting forecast error, measured in terms of Mean Absolute Percentage Error (MAPE), is shown in numerical values in Table 3. It was observed that MAPE is significantly low in case of neural network analysis.

TABLE 3. COMPARISON OF DEVIATIONS IN MAPE.

\begin{tabular}{|l|l|l|}
\hline Forecast method & $\begin{array}{l}\text { Forecast } \\
\text { period }\end{array}$ & $\begin{array}{l}\text { Forecast } \\
\text { (MAPE) \% }\end{array}$ \\
\hline Holt-Winter's model & weekly & 18.5 \\
\hline Holt-Winter's model & daily & 29.1 \\
\hline Fuzzy Neural network & daily & 10.1 \\
\hline
\end{tabular}

It is evident that Holt-Winter's model, although widely used in retail chain forecasting, becomes more erroneous when forecast is done more frequently, such as daily. But daily forecast is essential in case of fast moving items in a retail chain. On the other hand, neural network forecast provides less forecast error in case of daily forecast. Thus, neural network forecast is highly recommended in retail chain, especially in case of fast moving items.

\section{CONCLUSION}

Demand forecasting is vital in the overall supply chain in retail organizations. As numbers of variables affect the demand, thereby creating nonlinearity in demand functions, demand estimation becomes highly complex. Although several advanced forecasting techniques, such as BoxJenkins method, Holt-Winter's model, etc. are in place, their error level increase with increase in forecast frequency or alternatively decrease in forecast periods. In such a situation, fuzzy artificial neural network (ANN) can provide a better solution.

\section{REFERENCES}

[1] J. Aastrup and H. Kotzab, "Analyzing out-of-stock in independent grocery stores: an empirical study", International Journal of Retail and Distribution Management, vol. 37, issue 9, pp. 765 - 789, 2009.

[2] A. Ayad, "Optimizing inventory and store results in big box retail environment", International Journal of Retail \& Distribution Management, vol. 36, issue 3, pp. 180-191, 2008.

[3] A. P. Da-Silva, V. H. Ferreira and R. M. Velasquez, "Input space to neural network based load forecasters", International Journal of Forecasting, vol. 24, issue 4, pp. 616-629, 2008.

[4] T. Juster, "Advanced forecasting options for optimal supply chain performance: variable methods for dynamic markets", AMR Research Note, pp. 234-245, 2006.

[5] M. A. A. Hasin, "Inventory cost comparisons of retailer and manufacturer in a two stage supply chain", International Conference on Manufacturing Management, 2-4 March, 2008, Bangkok, pp. 173182.

[6] A. Syntetos, K. Nikolopoulos, and J. E. Boylan, "Judging the judges through accuracy-implication metrics: The case of inventory forecasting", International Journal of Forecasting, vol. 26, issue 1, pp. 134-143, 2010.

[7] L. M. De-Menezes and N. Y. Nikolaev, "Forecasting with genetically programmed polynomial neural networks", International Journal of Forecasting, vol. 22, issue 2, pp. 249-265, 2006.

[8] R. Fildes, P. Goodwin, M. Lawrence and K. Nikolopoulos, "Effective forecasting and judgmental adjustments: an empirical evaluation and strategies for improvement in supply-chain planning", International Journal of Forecasting, vol. 25, issue 1, pp. 3-23, 2009.

[9] M. Hokey, "Application of a decision support system to strategic warehousing decisions", International Journal of Physical Distribution and Logistics Management, vol. 39, issue 4, pp. 270-281, 2009.

[10] M. Nakano, "Collaborative forecasting and planning in supply chains: The impact on performance in Japanese manufacturers", International Journal of Physical Distribution and Logistics Management, vol. 39, issue 2, pp. 84-105, 2009.

[11] P. Jonsson and M. Gustavsson, "The impact of supply chain relationships and automatic data communication and registration on forecast information quality", International Journal of Physical Distribution and Logistics Management, vol. 38, issue 4, pp. 280-295, 2008.

[12] Q. Song and B. S. Chissom, "Forecasting enrollments with fuzzy time series : Part I", Fuzzy Sets and Systems, vol. 54, pp. 1-9, 1996.

[13] M. Qi and G. P. Zhang, "An investigation of model selection criteria for neural network time series forecasting", European Journal of Operational Research, vol. 132, pp. 666-680, 2001.

[14] N. Holt and G. Winter, "Advanced Exponential Smoothing techniques for seasonal effect and trend", International Journal of Forecasting, vol. 3, issue 1, pp. 12-23, 1987.

[15] C. Eroglu and K. L. Croxton, "Biases in judgmental adjustments of statistical forecasts: The role of individual differences", International Journal of Forecasting, vol. 26, issue 1, pp. 116-133, 2010.

[16] D. B. Grant and J. Fernie, "Exploring out-of-stock and on-shelf availability in non-grocery, high street retailing", International Journal of Retail and Distribution Management, vol. 4, issue 4, pp. 661-672, 2008.

[17] L. Trapani and G. Urga, "Optimal forecasting with heterogeneous panels: A Monte Carlo approach", International Journal of Forecasting, vol. 25, issue 3, pp. 567-586, 2009.

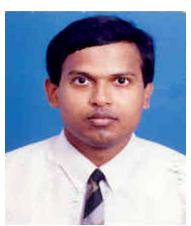

Dr. M. Ahsan Akhtar Hasin obtained his B.Sc. Eng. in Electrical and Electronic Engineering from BUET, Dhaka, Bangladesh, M. Sc. Eng. and Ph.D. in Industrial Systems Engineering from the Asian Institute of Technology (AIT), Bangkok, Thailand. Currently he is a Professor of the Department of Industrial and Production Engineering, Bangladesh University of Engineering and Technology (BUET).

He has 21 years of teaching and research experience in Bangladesh, Thailand and Vietnam. He has authored several textbooks and chapters in books, published from the USA and Bangladesh. He has in his credit a large number of international journal publications too. His one of the research publications was awarded the "best research publication" in the world in year 2001 .

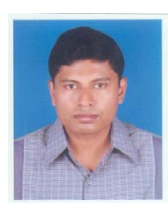

Shuvo Ghosh obtained his B.Sc. Eng. and M. Sc. Engineering in Industrial Engineering from BUET, Dhaka, Bangladesh. He is an Assistant Professor of the same. Currently, he is pursuing $\mathrm{Ph}$. D. in the USA.

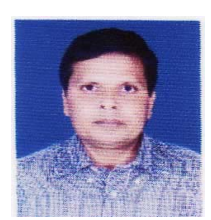

Dr. Mahmud Akhtar Shareef obtained his B.Sc Engineering in civil engineering from BUET, Dhaka, Master of Business Administration from IBA, Dhaka University, an M. Eng. in Civil Eng. from Carleton University, Canada and a Ph.D. in Business Administration from Carleton University, Canada. He is currently an Associate Professor in North South University, Bangladesh. He has in his credit a large number of Books and Journal papers. 